\title{
Acute generalized exanthematous pustulosis induced by piroxicam
}

\section{Pustulosis exantemática generalizada aguda inducida por piroxicam}

\author{
Ingrid Bissinger, ${ }^{1}$ Gustavo Matute-Turizo, ${ }^{2}$ María Natalia Mejía-Barreneche ${ }^{2}$
}

\begin{abstract}
Background: Between 62 and $90 \%$ of cases of acute generalized exanthematous pustulosis are caused by drugs. Its onset is rapid with generalized pustules, fever, and blood neutrophil count over 7000; pustules resolve spontaneously in less than 15 days. A case associated with piroxicam described.

Case report: A 36-year-old with initial erythema of the thorax and abdomen, accompanied by burning, without fever, which later spread to his forearms, upper arms, and thighs, with face edema. A week earlier he had taken piroxicam for low back pain; at the time of hospitalization he received antihistamines, and topical and systemic steroids. Full blood count showed leukocytes at 8920, eosinophils at 600, neutrophils at 6600, total serum IgE at $188 \mathrm{UI}$, C-reactive protein at $2.9 \mathrm{mg} / \mathrm{L}$, and no liver, kidney, or lung involvement. Treatment was initiated with intravenous antihistamines and ranitidine, saline, topical Vaseline plus topical mupirocin, and systemic steroids. On the second day of hospitalization neutrophils increased to 9000 and PCR to 3.3. The score to evaluate acute exanthematous pustulosis in the patient was 8 , giving a definitive diagnosis.

Conclusions: The differential diagnosis should be established primarily with pustular psoriasis. The prognosis is generally good, as reported.
\end{abstract}

Keywords: Acute generalized exanthematous pustulosis; Drug eruptions; Piroxicam

Este artículo debe citarse como: Bissinger I, Matute-Turizo G, Mejía-Barreneche MN. Pustulosis exantemática generalizada aguda inducida por piroxicam. Rev Alerg Mex. 2016;63(4):408-412

${ }^{1}$ Clínica El Rosario Sede Tesoro. Medellín, Antioquia, Colombia ${ }^{2}$ Universidad Pontificia Bolivariana, Facultad de Medicina. Medellín, Antioquia, Colombia
Correspondencia: Ingrid Bissinger.

ingridbissingern@yahoo.com

Recibido: 2016-02-26

Aceptado: 2016-06-29 


\begin{abstract}
Resumen
Antecedentes: Entre 62 y 90\% de los casos de pustulosis exantemática generalizada aguda son causados por medicamentos. Su inicio es rápido con pústulas generalizadas, fiebre, conteo de neutrófilos en sangre mayor de 7000; la resolución de las pústulas es espontánea en menos de 15 días. Se describe un caso asociado a piroxicam.

Caso clínico: Hombre de 36 años de edad con eritema inicial en tórax y abdomen, acompañado de ardor, sin fiebre, que posteriormente se extendió a antebrazos, brazos y muslos; con edema de cara. Una semana antes había consumido piroxicam por dolor lumbar; al momento de su hospitalización recibía antihistamínicos, esteroides tópicos y sistémicos. El hemoleucograma mostró leucocitos de 8920, eosinófilos de 600, neutrófilos de 6600, IgE sérica total de $188 \mathrm{mg} / \mathrm{L}$, proteína $C$ reactiva de $2.9 \mathrm{mg} / \mathrm{L}$, sin compromiso hepático, renal ni pulmonar. Se inició tratamiento con antihistamínicos y ranitidina intravenosos, solución salina, vaselina tópica más mupirocina tópica y esteroides sistémicos. Al segundo día de hospitalización, los neutrófilos aumentaron a 9000 y la proteína C reactiva a $3.3 \mathrm{mg} / \mathrm{L}$. La puntuación para validar pustulosis exantemática aguda en el paciente fue de 8 , indicativa de diagnóstico definitivo.

Conclusiones: El diagnóstico diferencial debe establecerse principalmente con psoriasis pustulosa. El pronóstico en general es bueno, como sucedió con el caso informado.

Palabras clave: Pustulosis exantemática generalizada aguda; Erupciones por medicamentos; Piroxicam
\end{abstract}

\section{Antecedentes}

La pustulosis exantemática generalizada aguda es una reacción adversa severa cutánea poco común, causada principalmente por medicamentos. $\mathrm{Su}$ incidencia anual es de aproximadamente 1 a 5 casos por cada millón de personas. Se puede presentar a cualquier edad y en ambos sexos. Se caracteriza por pústulas estériles pequeñas, no foliculares intraepidérmicas y subcorneales de inicio abrupto, fiebre mayor de $38^{\circ} \mathrm{C}$ y eritema edematoso confluente. El cuadro clínico se inicia entre 1 y 21 días después de que se administra el medicamento. ${ }^{1,2}$

Comienza frecuentemente en cara o en grandes pliegues como área axilar submamaria, para después generalizarse. En ocasiones puede presentarse en áreas circunscritas o localizadas, por lo general en la cara; para esta presentación localizada se usa el término ALEP. ${ }^{3}$ Se acompaña de prurito o ardor. Puede existir compromiso de palmas, plantas y mucosas, oral, conjuntival o genital. Ocasionalmente hay adenopatías cervicales. En forma muy rara puede producirse púrpura (especialmente en las piernas), ampollas, signo de Nikolsky o lesiones en Diana atípicas, como en el síndrome de Stevens-Johnson o necrólisis epidérmica tóxica, por lo cual se considera un síndrome de sobreposición. ${ }^{2,4,5}$
Diversos medicamentos han sido identificados como desencadenantes de la pustulosis exantemática aguda generalizada, incluyendo los antiinflamatorios no esteroideos, pero existen pocos casos por piroxicam. ${ }^{6}$

\section{Caso clínico}

Hombre de 36 años de edad con antecedente de rinitis intermitente leve, sin antecedente personal ni familiar de psoriasis, quien acudió a urgencias por eritema inicial en el lado derecho del tórax y abdomen acompañado de ardor, sin fiebre, de cuatro días de evolución, el cual se había extendido a antebrazos, parte interna de los brazos y tercio superior de los muslos; también presentaba leve compromiso axilar e inguinal y edema de cara. Una semana antes había consumido piroxicam por dolor lumbar. Antes de presentarse a urgencias había recibido atención por las áreas de medicina general y dermatología, donde se había prescrito tratamiento con antihistamínicos, esteroides tópicos y esteroides sistémicos. Al ingreso se encontraba afebril, con múltiples micropústulas sobre piel eritematosa y edematosa (Figura 1), sin signo de Nikolsky, púrpura ni lesiones en Diana, con leve ulceración de mucosa oral, pero sin compromiso conjuntival. 


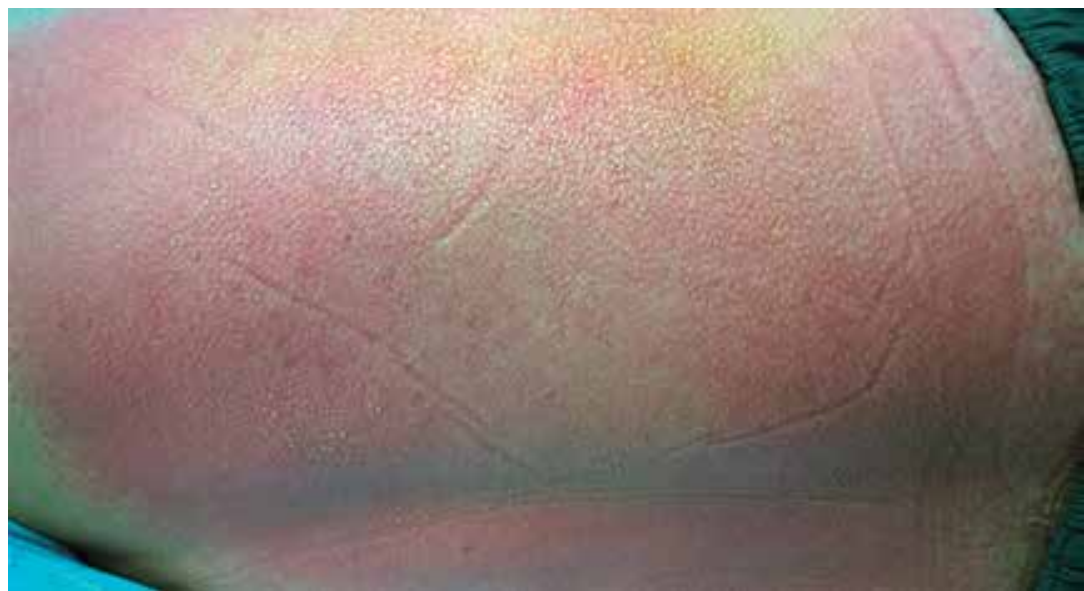

Figura 1. Múltiples micropústulas sobre piel eritematosa y edematosa de base.

El hemoleucograma mostró cuentas de leucocitos de 8920, de eosinófilos de 600 y de neutrófilos de 6600, IgE sérica total de 188 UI, proteína $\mathrm{C}$ reactiva de $2.9 \mathrm{mg} / \mathrm{L}$, sin compromiso hepático, renal ni pulmonar. No se realizó estudio bacteriológico de las pústulas. Se inició tratamiento con antihistamínicos y ranitidina intravenosos, solución salina, vaselina tópica más mupirocina tópica y esteroides sistémicos.

Por la ruptura de las pústulas y la posible sobreinfección, el servicio de dermatología indicó la administración de cefalexina. Al segundo día de

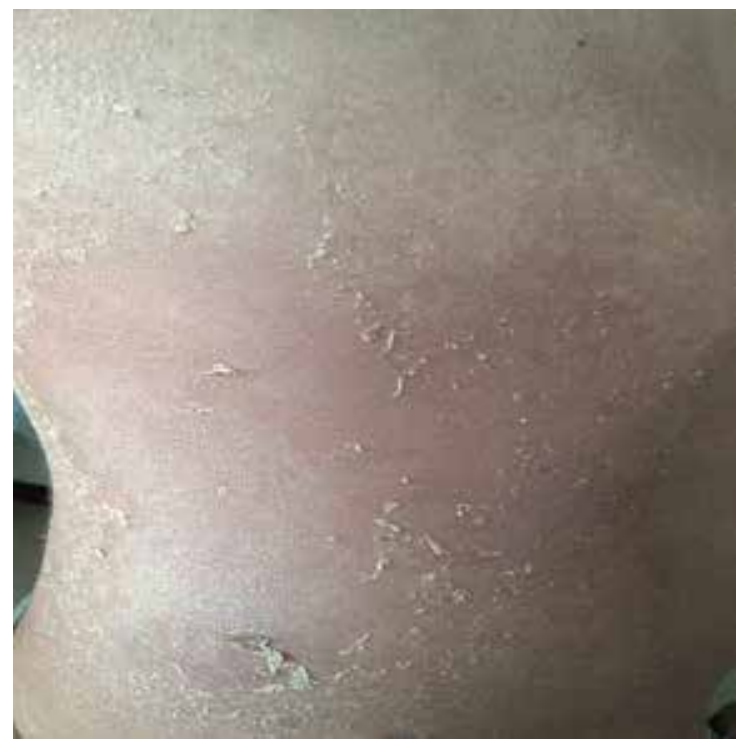

Figura 2. Descamación en tórax y abdomen. hospitalización los neutrófilos aumentaron a 9000 y la proteína $C$ reactiva a $3.3 \mathrm{mg} / \mathrm{L}$.

$\mathrm{Al}$ tercer día de hospitalización, el paciente se encontraba sin compromiso de los órganos internos, por lo que fue dado de alta. La descamación comenzó al décimo día de iniciado el cuadro (Figura 2).

En la biopsia de las lesiones se observó epitelio escamoso con acantosis e hiperqueratosis, elongación de la red de crestas y queratinocitos necróticos. En la dermis superficial se apreciaba edema e infiltrado inflamatorio mononuclear intersticial y perivascular y algunos eosinófilos, con exocitosis de algunos leucocitos polimorfonucleares. Se identificó pústulas intraepidérmicas con escasos elementos inflamatorios, pústulas subcórneas con abundantes polimorfonucleares neutrófilos que formaban abscesos y pústulas epidérmicas con ulceración y formación de abscesos (Figura 3).

La puntuación para validar pustulosis exantemática generalizada aguda del instrumento integrado por el Grupo de Estudio Euroscar indicó lo siguiente:

- Morfología de lesiones: pústulas típicas 2, eritema típico 2, distribución compatible 1; descamación pospustular, sí 1.

- Curso: compromiso de membranas, sí -2; inicio agudo 0 , resolución menor de 15 días, sí 0 ; fiebre, no 0 ; neutrófilos, sí 1 .

- Histología: pústulas subcorneales/intraepidérmicas más edema 3.

La puntuación total fue de 8 , indicativa de diagnóstico definitivo. 


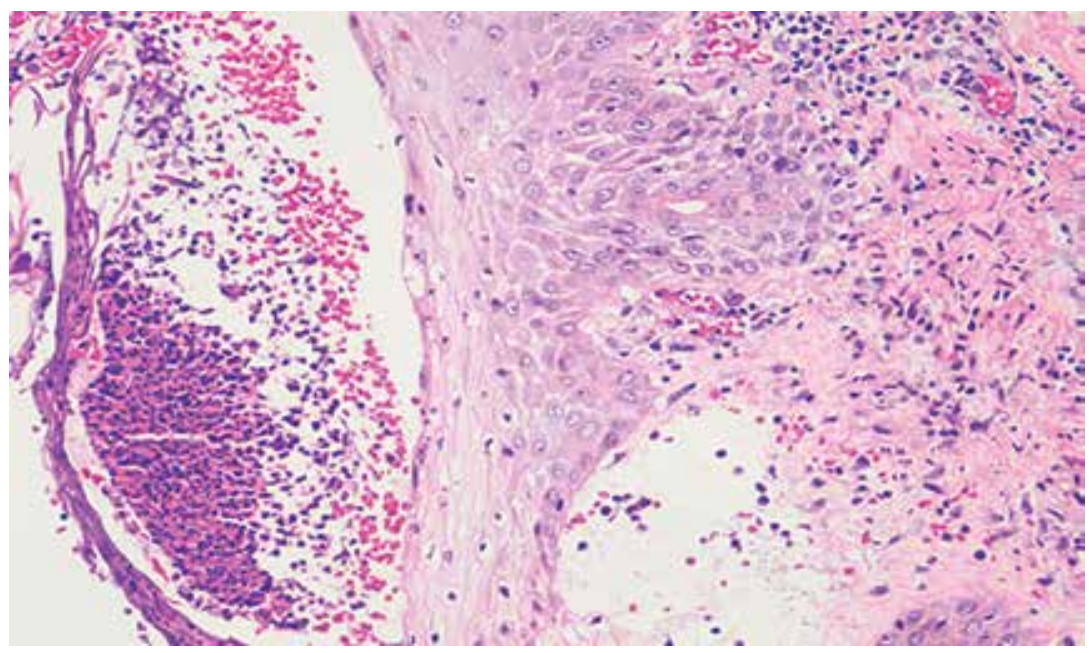

Figura 3. Pústulas subcórneas con abundantes polimorfonucleares neutrófilos que forman abscesos.

\section{Discusión}

Se ha informado de pacientes con pustulosis exantemática generalizada aguda que presentaron compromiso sistémico con elevación de los valores de las pruebas de la función hepática y hepatomegalia, anemia, falla respiratoria aguda, hipotensión, aumento de urea y creatinina, falla renal aguda, colestasis y compromiso medular. ${ }^{7}$

Luego de iniciado el cuadro hay descamación puntiforme y la enfermedad suele durar 15 días. En general tiene un pronóstico favorable y la mortalidad es de 0 a $5 \%{ }^{4}$

La biopsia indica pústulas intraepidérmicas o subcorneales espongiformes asociadas con uno o más de las siguientes alteraciones: edema de dermis, vasculitis, eosinófilos perivasculares o necrosis focal de queratinocitos. Hay infiltrado perivascular dérmico leve e infiltrado intersticial mixto, sin vasos sanguíneos dilatados o tortuosos ni cambios de psoriasis como acantosis y papilomatosis. ${ }^{2}$

El instrumento clínico propuesto por el Grupo de Estudio Euroscar para la validación de la pustulosis exantemática generalizada aguda es el más utilizado; en él se evalúa morfología, curso de la enfermedad e histología. $^{2}$

Aun cuando la indicación principal es retirar el medicamento implicado y dar tratamiento de soporte, es frecuente la prescripción de antihistamínicos para aliviar el prurito, así como esteroides venosos, orales o tópicos. ${ }^{8}$

Si bien existen pocos casos de pustulosis exantemática generalizada aguda por piroxicam, ${ }^{6}$ su número ha ido en aumento, al igual que los medicamentos implicados. El diagnóstico diferencial debe establecerse principalmente con psoriasis pustulosa. El pronóstico en general es bueno, como en el caso descrito.

\section{Referencias}

1. Chang SL, Huang $\mathrm{YH}$, Yang $\mathrm{CH}$, Hu S, Hong HS. Clinical manifestations and characteristics of patients with acute generalized exanthematous pustulosis in Asia. Acta Derm Venereol. 2008;88(4):363-365. doi: 10.2340/00015555-0438

2. Sidoroff A, Halevy S, Bavinck JN, Vaillant L, Roujeau JC. Acute generalized exanthematous pustulosis (AGEP) -a clinical reaction pattern. J Cutan Pathol. 2001;28(3):113-119.

3. Prange B, Marini A, Kalke A, Hodzic-Avdagic N, Ruzicka T, Hengge UR. [Acute localized exanthematous pustulosis (ALEP)]. J Dtsch Dermatol Ges. 2005;3(3):210-212.

4. Hotz C, Valeyrie-Allanore L, Haddad C, Bouvresse S, Ortonne N, Duong TA, et al. Systemic involvement of acute generalized exanthematous pustulosis: a retrospective study on 58 patients. $\mathrm{Br} \mathrm{J}$ Dermatol. 2013;169(6):1223-1232. doi: 10.1111/bjd.12502 
5. Poeschl MD, Hurley MY, Goyal SD, Vidal Cl. Targetoid eruptions: Acute generalized exanthematous pustulosis. Am J Dermatopathol. 2014;36(10):827-828, 838. doi: 10.1097/DAD.0000000000000167

6. Cherif Y, Jallouli M, Mseddi M, Turki H, Bahloul Z. Acute generalized exanthematous pustulosis induced by piroxicam: A case report. Indian J Pharmacol. 2014;46(2):232-233. doi: 10.4103/0253-7613.129332

7. Bourkia M, Charlès L, Lambotte O, Orostegui-Giron L, Goujard C, Ghosn J. Life-threatening acute generalized exanthematous pustulosis induced by two different protease inhibitors in an HIV-1-infected patient. J Antimicrob Chemother. 2011;66(9):2188-2189. doi: 10.1093/jac/dkr227

8. Guevara-Gutiérrez E, Uribe-Jiménez E, Díaz-Canchola M, Tlacuilo-Parra A. Acute generalized exanthematous pustulosis: Report of 12 cases and literature review. Int J Dermatol. 2009;48(3):253-258. doi: 10.1111/j.1365-4632.2009.03908.x 